\title{
Malignant testicular tumours in non-twin brothers
}

\author{
P. J. FINAN \\ F.R.C.S.
}

\author{
St James's University Hospital, Leeds 9
}

\begin{abstract}
Summary
Multiple examples of testicular tumours within a family are rare and the Testicular Tumour Panel noted a familial incidence in only $0.5 \%$ of 995 cases reported. A further case of testicular tumours in non-twin brothers is reported together with a brief review of previous publications.
\end{abstract}

\section{Case 1}

A 24-year-old man presented with a 6-month history of pain and swelling of the right testis. Examination revealed a hard, irregular, enlarged testis and signs of a pleural effusion. Chest X-ray confirmed the effusion together with widespread secondary spread.

A right orchidectomy was performed and the testis found to be replaced by a malignant trophoblastic teratoma.

Post-operatively he rapidly deteriorated and died. At post-mortem, secondary spread was found in the lungs, liver, brain and kidney.

\section{Case 2}

A 26-year-old man presented with a swelling of the right testis. Despite its being present for 6 months, and the death of his brother, medical advice was not sought sooner.

Examination revealed a large swollen right testis. A right orchidectomy was performed and the testis found to be replaced with seminoma.

Postoperatively he was treated with a course of radiotherapy and is alive and well 2 years later.

\section{Discussion}

Testicular tumours are rare, the incidence being $2-3 / 100000 \mathrm{men} / \mathrm{year}$ in the United Kingdom. The Testicular Tumour Panel noted a familial incidence in $0.5 \%$ of 995 cases reported to them (Collins and Pugh, 1964). Single case reports have appeared since the first recorded case by Raven (1934). Both similar (Young and Bohne, 1972) and dissimilar (Hutter, Lynch and Shnider, 1967) tumours have been reported. Gulley, Kowalski and Neuhoff (1974) recorded a family with 4 similarly affected brothers. Kademian and Caldwell (1976) reported a further family and comprehensively reviewed testicular tumours in closely related family members. A further case of familial testicular teratomas has appeared since then (Thompson and Sinclair, 1977). This would appear to be the thirteenth reported case of familial testicular tumours in non-twin brothers.

\section{Acknowledgment}

I thank Mr J. B. M. Roberts, Consultant Urologist, Bristo! Royal Infirmary, for allowing me to report these cases under his care.

\section{References}

Collins, D.H. \& Pugh, R.C.B. (1964) The pathology of testicular tumours. British Journal of Urology (Supplement) p. 8.

Gulley, R.M., Kowalski, R. \& Neuhoff, C.F. (1974) Familial occurrence of testicular neoplasms. A case report. Journal of Urology, 112, 620.

Hutter Jr, A.M., LYNCH, J.J. \& ShNider, B.I. (1967) Malignant testicular tumours in brothers. Journal of the American Medical Association, 199, 1009.

Kademian, M.T. \& Caldwell, W.L. (1976) Testicular seminoma: a case report of 2 brothers and a review of the literature of testicular malignancies occurring in closely related family members. Journal of Urology, 116, 380.

RAVEN, R.W. (1934) Tumours of the testis in two brothers. Lancet, ii, 870.

Thompson, W.O. \& Sinclair, D.M. (1977) Familial teratoma of testis. British Journal of Urology, 49, 322.

Young, J.A. \& BoHNE, A.W. (1972) Seminona in non-twin brothers: a case report. Journal of Urology, 107, 1000. 